\title{
Genistein inhibits growth of human uveal melanoma cells and affects microRNA-27a and target gene expression
}

\author{
QINGMIN SUN ${ }^{1 *}$, RIHONG CONG ${ }^{1 *}$, HONGLI YAN ${ }^{2 *}$, HAIJUAN GU $^{1}$, \\ YING ZENG ${ }^{1}$, NANNAN LIU ${ }^{1}, \mathrm{JIE} \mathrm{CHEN}^{1}$ and BIN WANG ${ }^{1}$ \\ ${ }^{1}$ Department of Pharmacology, Nanjing Medical University, Nanjing, Jiangsu Province 210029; \\ ${ }^{2}$ Dongzhi Health Inspection Bureau, Dongzhi, Anhui Province 247200, P.R. China
}

Received March 5, 2009; Accepted May 25, 2009

DOI: $10.3892 /$ or_00000472

\begin{abstract}
Genistein, an isoflavone isolated from soybean, has been found to be a potent antitumor agent. However, both the effect of genistein on human uveal melanoma cells and the precise mechanism by which genistein suppresses tumorigenesis remain unclear. In the present study, we explored the possible activity of genistein to inhibit human uveal melanoma cell growth and investigated the possible role of genistein on microRNA-27a (miR-27a) as well as its target gene zinc finger and BTB domain containing 10 (ZBTB10) expression levels. The results suggested a significant inhibition of uveal melanoma cell growth in a time- and dose-related manner. In vivo study also indicated treatment groups with genistein could significantly inhibit the growth of xenografts. Further functional assays revealed that the levels of miR-27a and its target gene ZBTB10 were significantly different based on the dose of genistein. In conclusion, the present study demonstrates that genistein exerts growth inhibitory activities in human uveal melanoma cells. Moreover, we for the first time report a correlation between antitumor activity of genistein and miR27 a mediated regulatory mechanism.
\end{abstract}

\section{Introduction}

Uveal melanoma is the most common primary malignant tumor of the eye in adults (1). It is associated with a high mortality rate due to early hematogenous dissemination and preferentially affects the liver (2,3). In the past decades, despite the development of more diagnostic techniques and the introduction of new treatment modalities, the mortality of

Correspondence to: Dr Bin Wang, Department of Pharmacology, Nanjing Medical University, 140 Hanzhong Road, Nanjing 210029, P.R. China

E-mail: binwang@njmu.edu.cn

${ }^{*}$ Contributed equally

Key words: genistein, uveal melanoma, microRNA-27a, zinc finger and BTB domain containing 10 uveal melanoma still have not significantly changed. Moreover, it has been found to be highly resistant to various chemotherapeutic drugs in uveal melanoma cells (4). Therefore, it is critical to improve understanding of the molecular pathogenesis of cancers and eventually develop new therapeutic drugs that can be effected by interfere with a specific pathway in uveal melanoma development or progression.

MicroRNAs (miRNAs), a novel group of endogenous non-coding small RNAs, which negatively regulate gene expression in post-transcriptional manner by interfering with target mRNA (5). Abnormal expression of miRNAs has been shown to play crucial roles in a variety of cellular processes including differentiation, apoptosis and cell proliferation $(6,7)$. A previous study showed that some special miRNAs can serve as both diagnostic markers and therapeutic targets for many different tumor types (8). Worley et al suggested that aberrant miRNA expression was considered as accurate biomarker for metastatic risk in uveal melanoma (9).

Genistein, an isoflavone isolated from soybean, has been reported to have the preventive and therapeutic effect on carcinogenesis and many other chronic diseases (10). It is widely considered as a classic tyrosine kinase inhibitor, which plays key roles in cell growth and apoptosis (11). In our previous study, we also found that genistein had an effect on the prevention and treatment of ocular neovascularization, by inhibiting vascular endothelial growth factor (VEGF) and basic fibroblast growth factor (bFGF) expression in cultured retinal pigment epithelium cells $(12,13)$. Previous studies indicated that genistein inhibited melaonoma cell growth apoptosis in vivo and in vitro $(14,15)$. Genistein has been revealed to inhibit the growth of various human cancers by affecting a wide variety of cellular processes and/or enzymes, such as cell cycle, apoptosis and angiogenesis, however, there is no related study between miRNA-mediated transcriptional modulation and the inhibitory effects of genistein on carcinogenesis. Moreover, both the effect of genistein on human uveal melanoma cells and the precise mechanism by which genistein suppresses tumorigenesis remain unclear. Therefore, we examined the effects of genistein on human uveal melanoma cells growth in vivo and in vitro and investigated the possible role of genistein on microRNA-27a and its target gene zinc finger and BTB domain containing 10 (ZBTB10) expression levels. MiR-27a is an oncogenic 
miRNA and has been reported to be widely expressed in various cancer cells $(16,17)$. In the present study, we hypothesized that genistein could affect human uveal melanoma vitality and analyzed whether genistein inhibits tumor growth by influencing the expression of miR-27a and its target gene.

\section{Materials and methods}

Chemicals. Genistein was purchased from Sigma (St. Louis, MO, USA). For cell culture experiments, genistein was dissolved in dimethyl sulfoxide (DMSO) (Sigma) and the final concentration of $0.05 \%$ DMSO. In vivo studies, genistein was dissolved in $1 \%$ DMSO to a desired concentration and was sonicated into suspension in $0.9 \%$ saline prior to injection.

Cell lines. The human uveal melanoma cell line C918 was kindly provided by Professor Elisabeth A. Seftor (Children's Memorial Research Center, Chicago, IL). The origin and characteristics of $\mathrm{C} 918$ cell line has been described previously (18). The cells were maintained in RPMI-1640 medium (Invitrogen) supplemented with $10 \%$ fetal bovine serum and $0.1 \%$ gentamycin sulfate in $37^{\circ} \mathrm{C}$ incubator with $5 \%$ carbon dioxide.

Cell growth and viability. The effect of genistein on the in vitro growth of C918 cells was determined by 3-(4,5-dimethylthiazol-2-yl)-2,5-diphenyltetrazolium bromide (MTT) assay. Briefly, the cells were plated at the density of $1 \times 10^{4}$ cells/ well onto a 96-well plate. After a $12 \mathrm{~h}$ preincubation, cells were exposed to different concentrations of genistein $(0,10$, $25,50,100$ and $200 \mu \mathrm{M}$ ) for $72 \mathrm{~h}$. Subsequently, $20 \mu \mathrm{l}$ of $0.5 \%$ MTT in phosphate-buffered saline (PBS) was added to each well and the incubation was continued for $4 \mathrm{~h}$ at $37^{\circ} \mathrm{C}$. At the end of the incubation period, the culture medium was replaced with $200 \mu \mathrm{l}$ of DMSO and the optical density of each well was determined with a spectrophotometer at $492 \mathrm{~nm}$. Eight duplicate wells were set up for each concentration sample.

Animal model. Six-week-old female BALB/C nu/nu mice were obtained from Vital River Laboratory Animal Technology (Beijing, China). They were kept under specific pathogenfree conditions in autoclaved cages and fed with sterilized food and water ad libitum. All experiments were performed in accordance with the official recommendations of the Chinese Community Guidelines. For in vivo injection, C918 cells were harvested when growing to $80-90 \%$ of confluence and washed twice with sterile PBS, then counted and resuspended in PBS at a density of $1 \times 10^{7} / \mathrm{ml}$. The suspension $(0.1 \mathrm{ml} / 10 \mathrm{~g}$ body weight) was injected subcutaneously into the nude mice. When tumor nodules were palpable, the mice were randomized into five groups. Following our previous experiment, genistein was used at concentrations of 25,50 and $100 \mathrm{mg} / \mathrm{kg}$ body weight/day intraperitoneally (i.p.), respectively. In brief, the groups were: group 1, untreated; group 2, control, injected with 1\% DMSO; group 3, genistein, $25 \mathrm{mg} / \mathrm{kg}$; group 4, genistein, $50 \mathrm{mg} / \mathrm{kg}$; group 5, genistein, $100 \mathrm{mg} / \mathrm{kg}$. The treatment was continued every day for 1 month. During this period, the xenograft volume was

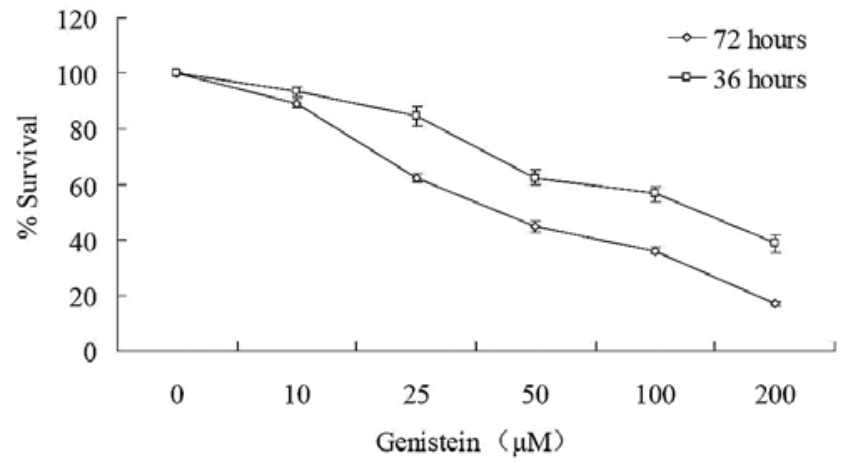

Figure 1. Effect of genistein on human uveal melanoma (C918) cell growth and viability. Cell viability of $\mathrm{C} 918$ cells was determined by MTT assay after 36 and $72 \mathrm{~h}$ stimulation with or without different concentrations of genistein. Each point represents the mean \pm SEM. This figure is a representative of three independent experiments.

measured by caliper every other day and was calculated by the formula: length $\mathrm{x}$ width ${ }^{2} \times 0.5$. At the study endpoint, the mice were sacrificed, the tumors were removed and weighed and livers were also collected. The inhibition rate (IR) of the tumor was determined using the formula:

IR $(\%)=(1-$ mean tumor weight of treatment group/mean tumor weight of control group).

Quantitative RT-PCR. Total RNA from C918 cells was extracted using TRIzol reagent (Invitrogen) according to the manufacturer's protocol. TaqMan microRNA assays (Applied Biosystems Inc.) were used to quantify miR-27a expression. Small nuclear RNA, U6B (Applied Biosystems Inc.), was treated as normalization control. ZBTB10 and TATA binding protein $(T B P)$ (control) mRNA levels were assessed by SYBR-Green quantitative PCR. Reactions were conducted according to manufacturer's instructions using Power SYBRGreen PCR Master Mix (Applied Biosystems Inc.). Forward (F) and reverse (R) primers were used as follows: ZBTB10, GCTGGATAGTAGTTATGTTGC and CTGAGTGGTTTG ATGGACAGA; TBP, TGCACAGGAGCCAAGAGTGAA and CACATCACAGCTCCCCACCA. All real-time amplifications were measured in triplicate and performed with the ABI Prism 7300 sequence detection system (Applied Biosystems Inc.). The fold-change of miR-27a and ZBTB10 mRNA was calculated using the $2-{ }^{\Delta \Lambda C T}$ method.

Statistics. All data was represented as the mean \pm SEM. The difference between the groups was determined by using the one-way ANOVA. A P-value of $<0.05$ was considered statistically significant. All the analyses were carried out with the SPSS 13.0 (SPSS Inc., Chicago, IL, USA) and were based on two-tailed probability.

\section{Results}

In vitro effect of genistein on C918 cell growth and viability. We investigated the effect of genistein on cell viability by MTT assay and the result suggested a significant inhibition of uveal melanoma cell growth in a time- and dose-related manner. As shown in Fig. 1, after a treatment period of $36 \mathrm{~h}$, genistein decreased cell proliferation by $\sim 60 \%$ in $200 \mu \mathrm{M}$ 
A

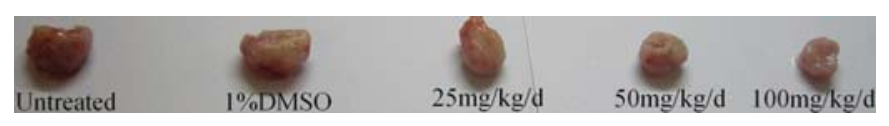

B

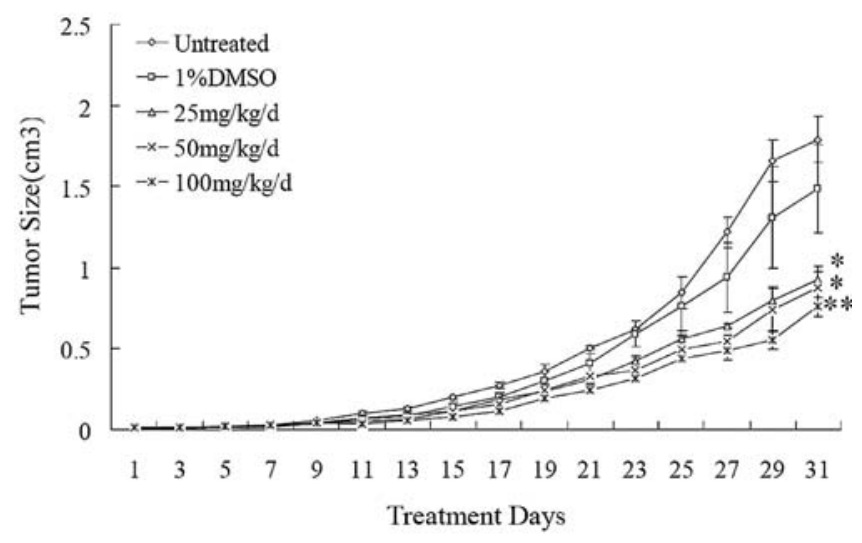

Figure 2. The inhibitory effect of genistein on the growth of uveal melanoma xenografts in nude mice. Animals were randomly assigned into five groups The treatment groups were injected i.p. with 25,50 and $100 \mathrm{mg} / \mathrm{kg}$ body weight/day of genistein, respectively. (A) Representative tumors in each experimental group are shown at the end of treatment. (B) Growth curves of xenografts revealed the mean tumor volume of the control and genistein treatment groups. Tumor size was determined as described in the Materials and methods. Data represent means \pm SEM., $n=4 .{ }^{*} \mathrm{P}<0.05 ;{ }^{* *} \mathrm{P}<0.01$ vs. control (1\% DMSO).

group compared to control cells. When the treatment was extended to $72 \mathrm{~h}$, the $50 \%$ inhibitory concentration $\left(\mathrm{IC}_{50}\right.$ ) value had decreased to $48.23 \mu \mathrm{M}$ and at higher concentration $(200 \mu \mathrm{M})$, the cell viability was only $16.7 \%$. These data suggested that genistein could markedly inhibit human uveal melanoma cell growth and viability.

In vivo impact of genistein on uveal melanoma xenografts. To study the effect of genistein on human uveal melanoma, we established an ectopic model of human uveal melanoma in 28 athymic nude mice. There were no difference on body weight before the study $(19.31 \pm 0.76 \mathrm{~g}, \mathrm{P}=0.590)$. When tumors were observed, we administered genistein to tumor model mice daily for 30 days. We found that all treatment groups with genistein significantly inhibited the growth of xenograft in vivo $(\mathrm{F}=8.849 ; \mathrm{P}=0.001)$ (Fig. 2). The tumors were harvested on the 37 th day and the average size of the tumors in the $100 \mathrm{mg} / \mathrm{kg}$ treatment group was $0.76 \pm 0.60 \mathrm{~cm}^{3}$, while for the control group, the average size was $1.49 \pm 0.27 \mathrm{~cm}^{3}$. The average size of the tumors in the other treatment groups were also smaller than the control group (data was not shown). However, there was no difference between untreated group and control group. In the present study, we also tested the tumor masses and the results showed that the inhibition rate of tumor growth for 25,50 and $100 \mathrm{mg} / \mathrm{kg}$ body weight/day genistein was $18.8 \%, 21.5 \%$ and $36.8 \%$ compared with the control group, respectively.

Effect of genistein on expression of $m i R-27 a$ and its target gene ZBTB10. In order to investigate whether genistein inhibits

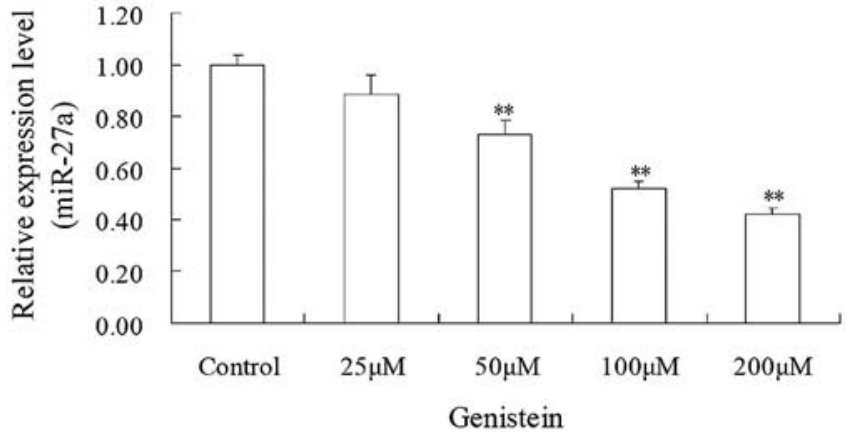

Figure 3. The effect of genistein on miR-27a expression in human uveal melanoma C918 cells. After being treated with $0,25,50,100$ and $200 \mu \mathrm{M}$ of genistein for $48 \mathrm{~h}$, miRNA was extracted and measured by TaqMan microRNA assays. The relative expression of miR-27a was normalized to that of the U6B small nuclear RNA gene (RNU6B) control. Data represent means $\pm \mathrm{SEM}, \mathrm{n}=4 .{ }^{* *} \mathrm{P}<0.01$ vs. control.

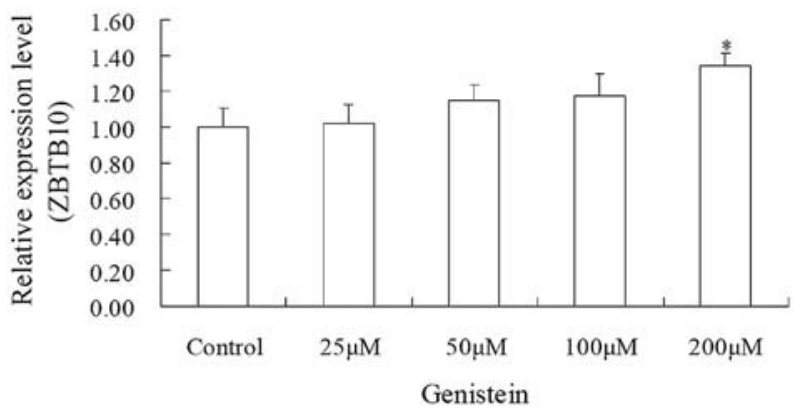

Figure 4. The effect of genistein on ZBTB10 expression in human uveal melanoma C918 cells. After being treated with 0,25, 50, 100 and $200 \mu \mathrm{M}$ of genistein for $48 \mathrm{~h}$, mRNA was extracted and assessed by SYBR-Green quantitative PCR. The relative expression of ZBTB10 mRNA normalization was performed with TATA binding protein $(T B P)$. Data represent means \pm SEM, $n=4 .{ }^{*} \mathrm{P}<0.05$ vs. control.

human uveal melanoma cell growth through affecting miR27a and its target gene expression, we measured their levels of expression by quantitative RT-PCR. The 'stem-loop' realtime PCR results indicated that genistein markedly inhibited miR-27a expression in a concentration-dependent manner. After the cells were treated with $25,50,100$ and $200 \mu \mathrm{M}$ of genistein for $48 \mathrm{~h}$, compared with the control, the levels of miR-27a were decreased to $88.9 \pm 6.9,72.9 \pm 5.4,51.7 \pm 3.2$ and $42 \pm 2.5 \%$, respectively (Fig. 3 ).

To verify whether the decreased level of miR-27a could ultimately influence the target gene transcription activity, we examined the expression level of the known target gene ZBTB10. As shown in Fig. 4, after $48 \mathrm{~h}$ treatment with genistein, ZBTB10 expression in $200 \mu \mathrm{M}$ genistein group was significantly higher than that in control group $(\mathrm{P}=0.037)$. These data suggested that genistein inhibited human uveal melanoma cell proliferation at least in part through endogenous microRNA-mediated pathway.

\section{Discussion}

It is widely accepted that tumor development and progression is a multi-step and multifocal field process involving genetic and non-genetic factors, such as the environment and diet. 
Previous studies indicated that diets containing a high intake of soy products and green tea had a beneficial effect on tumorigenesis $(19,20)$. Genistein, the predominant isoflavone found in soy, has been demonstrated to exert potential antitumor activity in a range of human cancer cell lines in vitro and in xenograft models. For example, Shao et al revealed that genistein exerted multiple suppressive effects on human breast carcinoma cells (21). Lakshman et al indicated that dietary genistein could inhibit metastasis of human prostate cancer (22). It has received wide attention by its potential healthbeneficial effects in the last few years (23). Therefore, to improve our understanding of genistein antitumor activity, we measured its effects on human refractory cancer-uveal melanoma. In the present study, we for the first time revealed that genistein concentration-dependently inhibited human highly aggressive uveal melanoma cells growth in vivo and in vitro. In the further functional assays, interestingly, we found that this effect was mediated, at least in part, through affecting miR-27a-associated regulatory mechanism.

To date, the mortality rate remains high because of the frequent occurrence of metastases and no effective chemotherapy has been developed for uveal melanoma patients. Therefore, it is necessary to develop an effective and non-toxic drug. It is well known that angiogenesis plays an important role in the development as well as the progression of solid tumors. Especially for malignant uveal melanoma, neovascularization is regarded as crucial step for metastasis. Our previous studies indicated that genistein 50, 100 and 200 $\mu \mathrm{M}$ dose-dependently inhibited ocular neovascularization by affecting VEGF, HIF1 $\alpha$ and bFGF expression $(12,13,24)$. In the current study, we observed that genistein had a dosedependent growth inhibition on human uveal melanoma cells in vitro and a tumor suppressor effect in vivo, possibly associated with the inhibitor activity on cell proliferation and angiogenesis. Similarly, Russo et al suggested that genistein reduced significantly the vitality of human melanoma M14 cells and showed a protective effect on ultraviolet lightinduced DNA damage (25). Record et al also indicated that genistein inhibited the growth of B16 melanoma cells in a dose- and time-related manner, the $\mathrm{IC}_{50}$ was only $35 \mu \mathrm{M}$ after $48 \mathrm{~h}$ treatment (14). Together, these investigations suggest that genistein exhibits strong antitumor effect in the human malignant melanoma. Moreover, Tamura et al indicated that genistein could enhance the chemosensitivity of melanoma patients (15).

MiRNAs, a class of novel posttranscriptional regulators, had aroused increasing interest in biological and medical sciences. Recent studies indicated that exogenous miRNAs played crucial roles in the development of multidrug resistance (MDR) in cancer cells (26-28). MiR-27a is located at chromosome 19 and has been shown to be widely expressed in breast cancer, gastric adenocarcinoma and cervical cancer $(16,17,29)$. Mertens-Talcott et al observed that transfection of antisense miR-27a (as-miR-27a) led to increased ZBTB10 levels in MDA-MB-231 breast cancer cells (17). Consistently, Scott et al also suggested that the oncogenic miR-27a suppressed ZBTB 10 expression, which interfere with transcription factor $S p l$ activation (30). Sp protein expression and activation play important roles in human tumor development and progression, by regulating cancer cell survival, growth, and angiogenesis (31-33). More recently, Zhu et al reported that miR-27a and miR-451 were involved in activating the MDR1 gene P-glycoprotein expression, which was associated with cancer cell resistance to a series of chemotherapeutics (34). In present experiments, we found that genistein modulated the expression levels of miR-27a and its target gene ZBTB10, which might be responsible for the effect on human uveal melanoma. Therefore, miR-27a and its target gene could be considered as targeted therapeutic strategy in cancer with resistant to traditional chemotherapeutic drugs.

In conclusion, the present study for the first time demonstrates that genistein exerts growth inhibitory activities in highly aggressive uveal melanoma cells in vivo and in vitro. Moreover, we for the first time reported the role of genistein on miR-27a and its target gene ZBTB10 expression in uveal melanoma. Combined with other observations, it is biologically plausible that the decrease of miR-27a expression resulting in post-transcriptional gene regulation in uveal melanoma cells might partly account for the inhibitive effect of genistein on human uveal melanoma. Further study is needed to clarify the mechanism underlying the interaction between the miR-27a and tumor chemoprevention of genistein. More importantly, we provide novel insights into the molecular mechanisms of genistein therapeutic actions. We expect our findings could eventually promote the development of chemo-interventions for uveal melanoma.

\section{Acknowledgements}

We gratefully thank Professor Elisabeth A. Seftor (Children's Memorial Research Center, Chicago, IL) for providing the human uveal melanoma cell lines. This study was supported by grants from the National Natural Science Foundation of China (No. 30672486), the Natural Science Foundation of Jiangsu Province (No. BK2006525), '333 Project' and 'Qinglan Project' Funding for the Young Academic Leader to B. Wang.

\section{References}

1. Singh AD and Topham A: Incidence of uveal melanoma in the United States: 1973-1997. Ophthalmology 110: 956-961, 2003.

2. Rajpal S, Moore R and Karakousis CP: Survival in metastatic ocular melanoma. Cancer 52: 334-336, 1983.

3. Diener-West M, Hawkins BS, Markowitz JA and Schachat AP: A review of mortality from choroidal melanoma. II. A metaanalysis of 5-year mortality rates following enucleation, 1966 through 1988. Arch Ophthalmol 110: 245-250, 1992.

4. Wöll E, Bedikian A and Legha SS: Uveal melanoma: natural history and treatment options for metastatic disease. Melanoma Res 9: 575-581, 1999.

5. Bartel DP: MicroRNAs: genomics, biogenesis, mechanism, and function. Cell 116: 281-297, 2004.

6. Hwang HW and Mendell JT: MicroRNAs in cell proliferation, cell death, and tumorigenesis. Br J Cancer 94: 776-780, 2006.

7. Chen CZ, Li L, Lodish HF and Bartel DP: MicroRNAs modulate hematopoietic lineage differentiation. Science 303: 83-86, 2004.

8. Gaur A, Jewell DA, Liang Y, Ridzon D, Moore JH, Chen C, Ambros VR and Israel MA: Characterization of microRNA expression levels and their biological correlates in human cancer cell lines. Cancer Res 67: 2456-2468, 2007.

9. Worley LA, Long MD, Onken MD and Harbour JW: MicroRNAs associated with metastasis in uveal melanoma identified by multiplexed microarray profiling. Melanoma Res 18: 184-190, 2008 . 
10. Dixon RA and Ferreira D: Genistein. Phytochemistry 60: 205-211, 2002.

11. Ullrich A and Schlessinger J: Signal transduction by receptors with tyrosine kinase activity. Cell 61: 203-212, 1990.

12. Wang B, Zou Y, Li H, Yan H, Pan JS and Yuan ZL: Genistein inhibited retinal neovascularization and expression of vascular endothelial growth factor and hypoxia inducible factor 1alpha in a mouse model of oxygen-induced retinopathy. J Ocul Pharmacol Ther 21: 107-113, 2005.

13. Pan JS, Zhu HJ, Zhang B, Li H, Yan H and Wang B: Inhibitive effect of genistein on hypoxia-induced basic fibroblast growth factor expression in human retinal pigment epithelium cells. J Ocul Pharmacol Ther 22: 103-109, 2006.

14. Record IR, Broadbent JL, King RA, Dreosti IE, Head RJ and Tonkin AL: Genistein inhibits growth of B16 melanoma cells in vivo and in vitro and promotes differentiation in vitro. Int J Cancer 72: 860-864, 1997.

15. Tamura S, Bito T, Ichihashi M and Ueda M: Genistein enhances the cisplatin-induced inhibition of cell growth and apoptosis in human malignant melanoma cells. Pigment Cell Res 16: 470-476, 2003.

16. Liu T, Tang H, Lang Y, Liu M and Li X: MicroRNA-27a functions as an oncogene in gastric adenocarcinoma by targeting prohibitin. Cancer Lett 273: 233-242, 2008.

17. Mertens-Talcott SU, Chintharlapalli S, Li X and Safe S: The oncogenic microRNA-27a targets genes that regulate specificity protein transcription factors and the G2-M checkpoint in MDAMB-231 breast cancer cells. Cancer Res 67: 11001-11011, 2007.

18. Seftor EA, Meltzer PS, Kirschmann DA, Pe'er J, Maniotis AJ, Trent JM, Folberg R and Hendrix MJ: Molecular determinants of human uveal melanoma invasion and metastasis. Clin Exp Metastasis 19: 233-246, 2002.

19. Farina HG, Pomies M, Alonso DF and Gomez DE: Antitumor and antiangiogenic activity of soy isoflavone genistein in mouse models of melanoma and breast cancer. Oncol Rep 16: 885-891, 2006.

20. Zhou JR, Yu L, Mai Z and Blackburn GL: Combined inhibition of estrogen-dependent human breast carcinoma by soy and tea bioactive components in mice. Int J Cancer 108: 8-14, 2004.

21. Shao ZM, Wu J, Shen ZZ and Barsky SH: Genistein exerts multiple suppressive effects on human breast carcinoma cells. Cancer Res 58: 4851-4587, 1998.

22. Lakshman M, Xu L, Ananthanarayanan V, Cooper J, Takimoto $\mathrm{CH}$, Helenowski I, Pelling JC and Bergan RC: Dietary genistein inhibits metastasis of human prostate cancer in mice. Cancer Res 68: 2024-2032, 2008.
23. Banerjee S, Li Y, Wang Z and Sarkar FH: Multi-targeted therapy of cancer by genistein. Cancer Lett 269: 226-242, 2008.

24. Wang B, Zou Y, Yuan ZL and Xiao JG: Genistein suppressed upregulation of vascular endothelial growth factor expression by cobalt chloride and hypoxia in rabbit retinal pigment epithelium cells. J Ocul Pharmacol Ther 19: 457-464, 2003.

25. Russo A, Cardile V, Lombardo L, Vanella L and Acquaviva R: Genistin inhibits UV light-induced plasmid DNA damage and cell growth in human melanoma cells. J Nutr Biochem 17: 103-108, 2006.

26. Fujita Y, Kojima K, Hamada N, Ohhashi R, Akao Y, Nozawa Y, Deguchi $\mathrm{T}$ and Ito $\mathrm{M}$ : Effects of miR-34a on cell growth and chemoresistance in prostate cancer PC3 cells. Biochem Biophys Res Commun 377: 114-119, 2008.

27. Gal H, Pandi G, Kanner AA, Ram Z, Lithwick-Yanai G, Amariglio N, Rechavi G and Givol D: MIR-451 and Imatinib mesylate inhibit tumor growth of glioblastoma stem cells. Biochem Biophys Res Commun 376: 86-90, 2008.

28. Xia L, Zhang D, Du R, Pan Y, Zhao L, Sun S, Hong L, Liu J and Fan D: miR-15b and miR-16 modulate multidrug resistance by targeting BCL2 in human gastric cancer cells. Int J Cancer 123: 372-379, 2008.

29. Wang X, Tang S, Le SY, Lu R, Rader JS, Meyers C and Zheng ZM: Aberrant expression of oncogenic and tumorsuppressive microRNAs in cervical cancer is required for cancer cell growth. PLoS ONE 3: e2557, 2008.

30. Scott GK, Mattie MD, Berger CE, Benz SC and Benz CC: Rapid alteration of microRNA levels by histone deacetylase inhibition. Cancer Res 66: 1277-1281 2006.

31. Wang L, Wei D, Huang S, Peng Z, Le X, Wu TT, Yao J, Ajani J and Xie K: Transcription factor Sp1 expression is a significant predictor of survival in human gastric cancer. Clin Cancer Res 9: 6371-6380, 2003.

32. Zannetti A, Del Vecchio S, Carriero MV, Fonti R, Franco P, Botti G, D'Aiuto G, Stoppelli MP and Salvatore M: Coordinate up-regulation of Sp1 DNA-binding activity and urokinase receptor expression in breast carcinoma. Cancer Res 60: 15461551,2000

33. Hosoi Y, Watanabe T, Nakagawa K, Matsumoto Y, Enomoto A, Morita A, Nagawa H and Suzuki N: Up-regulation of DNAdependent protein kinase activity and $\mathrm{Sp} 1$ in colorectal cancer. Int J Oncol 25: 461-468, 2004.

34. Zhu H, Wu H, Liu X, Evans BR, Medina DJ, Liu CG and Yang JM: Role of MicroRNA miR-27a and miR-451 in the regulation of MDR1/P-glycoprotein expression in human cancer cells. Biochem Pharmacol 76: 582-588, 2008. 